\title{
Microscopia confocal in vivo no diaǵnóstico de ceratite fúngica: relato de caso
}

\author{
In vivo confocal microscopy in the diagnosis of fungal keratitis: case report
}

\author{
Gustavo Victor ${ }^{1}$ \\ Milton Ruiz Alves ${ }^{2}$ \\ Walton Nosé ${ }^{3}$
}

Trabalho realizado no Eye Clinic Day Hospital - São Paulo (SP) - Brasil

${ }^{1}$ Doutor em Oftalmologia pela Universidade de São Paulo - USP - Ribeirão Preto (SP) - Brasil.

${ }_{2}^{2}$ Professor Livre Docente da USP - São Paulo (SP) Brasil.

${ }^{3}$ Professor Livre Docente da Universidade Federal de São Paulo - UNIFESP - São Paulo (SP) - Brasil. Professor Titular do Departamento de Oftalmologia da Universidade Metropolitana de Santos - UNIMES - Santos (SP) - Brasil.

Endereço para correspondência: Gustavo Victor. Av. República do Líbano, 1034 - São Paulo (SP) CEP 04502-001

E-mail: gustavo.victor@eyeclinic.com.b

Recebido para publicação em 04.10.2005

Versão revisada recebida em 04.12.2005

Aprovação em 23.12.2005

Nota Editorial: Depois de concluída a análise do artigo sob sigilo editorial e com a anuência do Dr. André Romano sobre a divulgação de seu nome como revisor, agradecemos sua participação neste processo.

\begin{tabular}{|c|}
\hline RESUMO \\
\hline Os autores relatam um caso em que a microscopia confocal in vivo ajudou \\
no diagnóstico e acompanhamento de ceratite fúngica. Realizou-se a \\
microscopia confocal in vivo em paciente com úlcera corneana, que há 30 \\
dias estava sendo tratada, sem obter melhora com uso de diversos \\
medicamentos tópicos. O paciente também tinha se submetido à coleta de \\
material corneano para análise laboratorial, com resultado negativo e \\
inconclusivo. Foi observado à microscopia confocal, hifas e coleções \\
infecciosas fúngicas. Dez dias após o diagnóstico confocal, o resultado \\
de nova coleta de material corneano revelou crescimento de Fusarium sp.
\end{tabular}

Descritores: Microscopia confocal/métodos; Córnea; Ceratite/diagnóstico; Infecções oculares fúngicas; Fusarium; Relatos de caso [tipo de publicação]

\section{INTRODUCÃO}

A ceratite fúngica pode acometer as camadas corneanas profundas, seu tratamento é, geralmente, prolongado e as medicações utilizadas são tóxicas, fazendo com que o diagnóstico precoce seja importante ${ }^{(1)}$.

A microscopia confocal é uma importante ferramenta clínica não invasiva para o estudo de todas camadas corneanas, ajudando no diagnóstico e acompanhamento das doenças corneanas ${ }^{(1-8)}$. Descreveremos a seguir, um caso de ceratite fúngica em que a microscopia confocal in vivo ajudou no diagnóstico e acompanhamento do tratamento.

\section{RELATO DO CASO}

Um paciente de 52 anos, masculino, refere irritação corneana em OE há trinta dias. Tinha sido tratado com uso tópico de antibiótico e posteriormente com associação de antibiótico e corticosteróide tópicos, sem obter melhora. Foi avaliado e tratado em mais dois outros serviços com uso tópico de tobramicina, cefalotina e gentamicina fortificados por doze dias, sem obter resultados satisfatórios. Então foi submetido à coleta de material corneano para análise laboratorial, sem resultado conclusivo. Com piora do quadro e desenvolvimento de úlcera corneana, foi referido a este serviço. Estava em uso tópico de ofloxacino a $0,3 \%$ de 4 em 4 horas, biguamida a $0,01 \%$ de 1 em 1 hora e de neomicina a $0,5 \%$ de 3 em 3 horas, há um dia.

Antecedentes pessoais: submeteu-se a LASIK em ambos os olhos há dois anos, ficando com -1,00 dioptria (D) em olho esquerdo. Teve descolamento de retina em olho esquerdo, submetido à vitrectomia com uso de gás e endolaser há 10 meses. Era usuário de lente de contato (LC) gelatinosa 
hidrofílica em olho esquerdo para correção de erro refrativo residual há 5 meses. Negava trauma ocular.

O paciente apresentou-se, à inspeção, com dor ocular e fotofobia, que dificultava a abertura espontânea das pálpebras. $\mathrm{O}$ olho direito (OD) apresentava acuidade visual sem correção (AVSC) 20/25 e com correção (-0,50 D) 20/20. O olho esquerdo (OE) apresentava AVSC de conta dedos a $50 \mathrm{~cm}$, sem melhora com correção. A motilidade ocular extrínseca estava sem alterações. A pressão intra-ocular (PIO) era $12 \mathrm{mmHg}$ em OD (tonometria de aplanação) e a medida bidigital da PIO de ambos os olhos estavam semelhantes (14:00 h). À biomicroscopia o OD apresentava: córnea transparente, lamela corneana pediculada bem posicionada, sem outras alterações de interesse; o $\mathrm{OE}$ apresentava: hiperemia conjuntival difusa com injeção ciliar, úlcera corneana com infiltrado esbranquiçado, medindo $3,5 \mathrm{~mm}$ de diâmetro, ovalada, atingindo o eixo visual e acometendo estroma do leito residual corneano (Figura 1). Não foram observadas alterações nas pálpebras, íris, cristalino e câmara anterior. O exame fundoscópico apresentou-se sem alterações em ambos olhos.

Na primeira avaliação neste serviço foi realizado exame de microscopia confocal in vivo (MC) em OE e nova coleta de material corneano para pesquisa laboratorial.
O MC utilizado foi ConfoScan $2.0^{\circledR}$ (Nidek ${ }^{\circledR}$ USA), equipado com lente objetiva Achroplan 40/0,75 W $\infty / 0$. O seu manuseio e funcionamento já foram descritos anteriormente ${ }^{(9-10)}$.

O exame microscópico in vivo da lesão no estroma anterior e médio revelou os seguintes achados: vários filamentos brancos medindo entre 200 e $400 \mu \mathrm{m}$ em comprimento e entre 4 e $8 \mu \mathrm{m}$ em espessura, paralelos ou inclinados até $45^{\circ}$ ao plano corneano, alguns ceratócitos ativados, aumento da refletividade do compartimento extra-celular (Figura 2) e coleções infecciosas com bordas bem definidas, contendo áreas de diferentes intensidades de refletividade em seu interior (Figura 3), não pertencentes à anatomia normal corneana à MC, além de edema corneano que dificultou a observação de algumas regiões da córnea. Estes achados se limitavam à localização da lesão corneana. O exame da córnea sadia não revelou alterações.

Com estes achados, semelhantes a outros relatados na literatura $^{(1,3-6,8)}$, associando-se o quadro clínico do paciente, foi iniciado tratamento para ceratite fúngica. Foi prescrito uso tópico de pirimetamina a $5 \%$ e uso oral de cetoconazol, $400 \mathrm{mg} / \mathrm{dia}$. O resultado da investigação laboratorial foram os seguintes:

Citologia: incontáveis polimorfonucleares neutrófilos íntegros e degenerados. Raros mononucleares. Numerosas células

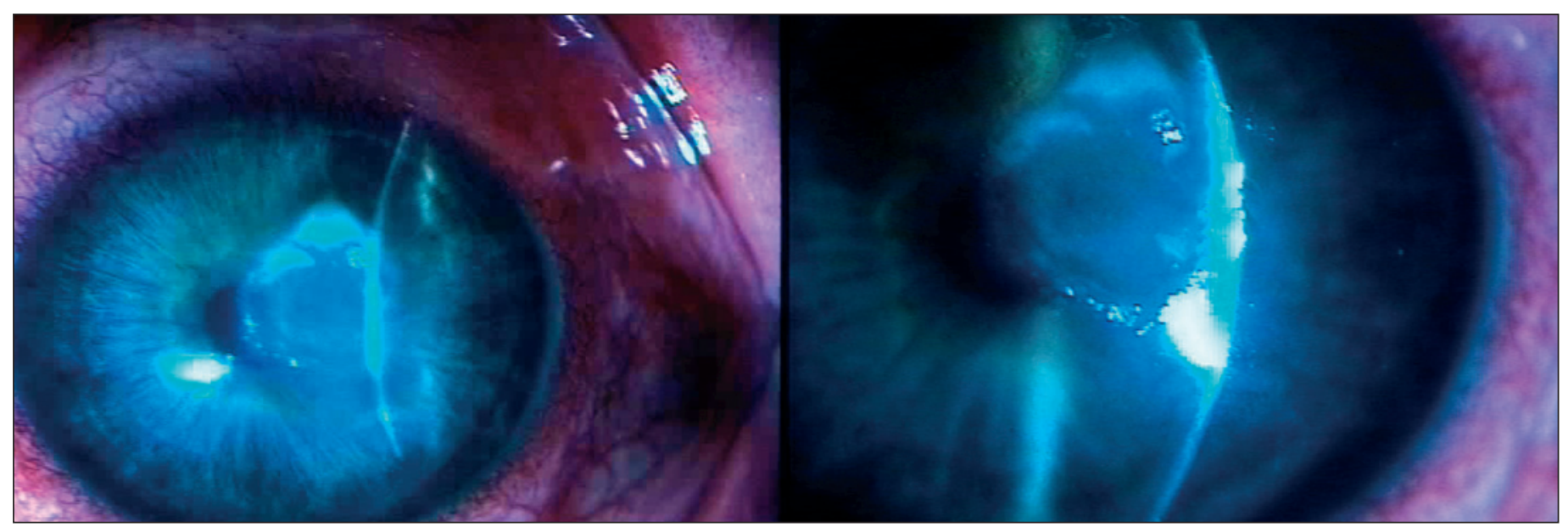

Figura 1 - Biomicroscopia do olho esquerdo
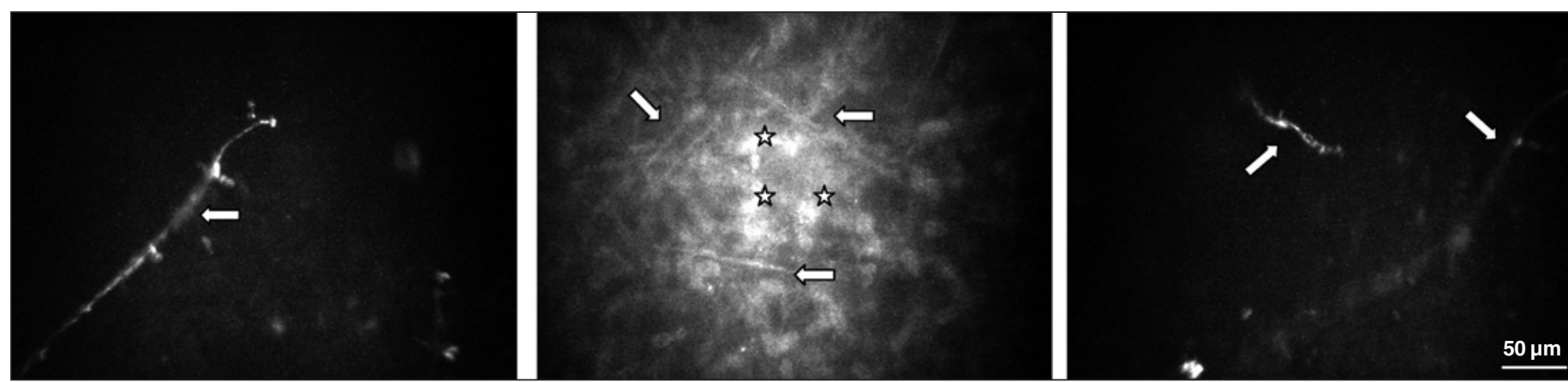

Figura 2 - Microscopia confocal in vivo da lesão corneana do olho esquerdo. Note os filamentos no estroma anterior e médio (setas) e os ceratócitos ativados $(*)$ 
epiteliais em queratinização e queratinizadas. Muco. Fibrina. Presença de grânulos de eosinófilos.

Bacterioscopia: ausência de bactérias.

Cultura para bactérias: negativa após 10 dias de incubação.

Cultura para fungos (resultado obtido após 10 dias - Figura 4): Fusarium sp.

O paciente foi submetido a avaliação biomicroscópica diária e a três exames com a MC (o inicial, após 15 dias e com 60 dias), ficando apenas com leucoma na região acometida, sem mais os achados da microscopia.

\section{DISCUSSÃO}

Estima-se que um terço das úlceras corneanas supostamente infecciosas têm cultura negativa ${ }^{(11-12)}$. Cerca de um quarto das culturas para fungos apresentam-se positivas apenas depois de
2 semanas $^{(13)}$. Essa demora no diagnóstico e tratamento pode contribuir para piora do prognóstico, inclusive favorecendo a possibilidade de perda da visão ${ }^{(14-15)}$. A MC, contribuindo com achados clínicos sugestivos que orientem o início do tratamento específico, pode evitar que muitos dos olhos com ceratite fúngica apresentem evolução desfavorável ${ }^{(2-3,14)}$. O diagnóstico pela microscopia confocal é difícil, mesmo quando o exame e sua interpretação sejam realizados por um operador experiente, podendo, algumas vezes, ser inconclusivo.

Neste estudo, a MC detectou hifas e coleções fúngicas. Alguns autores relatam que, nos estágios mais tardios de infecção corneana fúngica, a MC mostrou-se ser mais útil em revelar a presença da infecção do que a cultura no meio Sabouraud e a biópsia corneana. Outras técnicas para diagnóstico destes tipos de infecção foram descritas ${ }^{(3)}$. A "Polymerase chain reaction" (PCR) tem sido usada para o diagnóstico de ceratite fúngica, mas geralmente é muito demorada, tecnica-
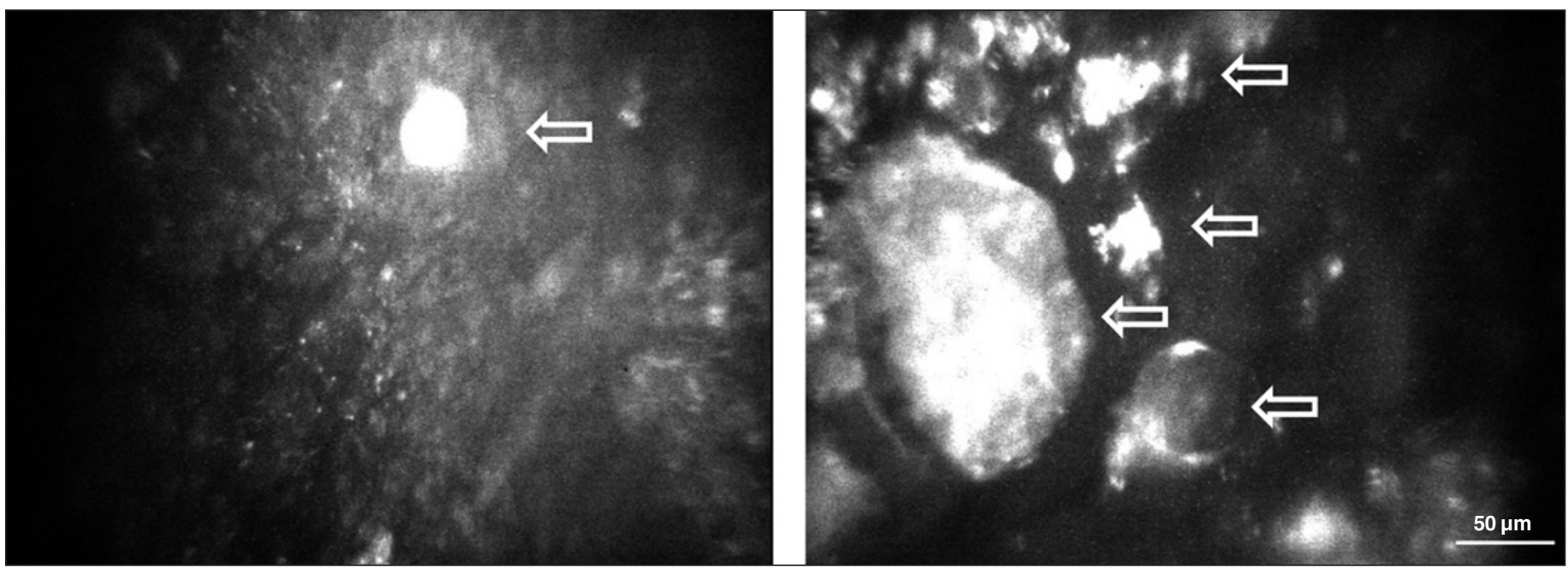

Figura 3 - Microscopia confocal in vivo da lesão corneana do olho esquerdo. Note as coleções infecciosas.

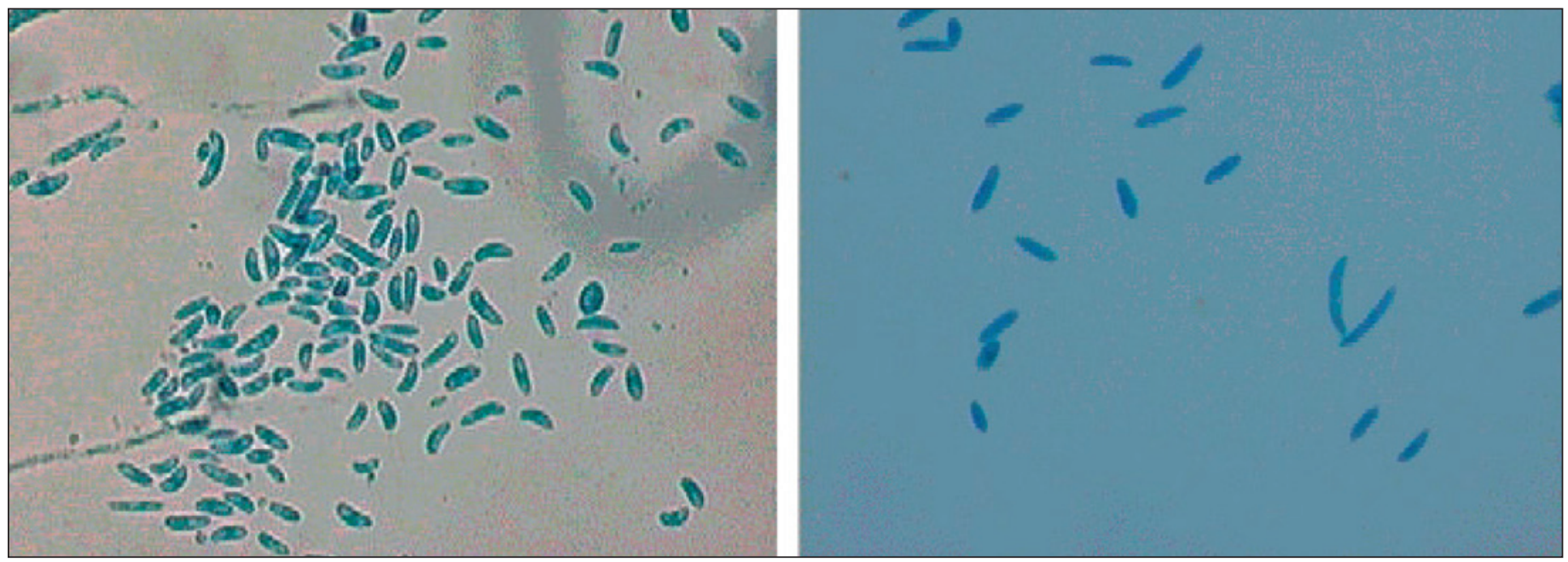

Figura 4 - Cultura para fungos: Fusarium sp 
mente difícil de ser realizada e nem sempre obtém resultados consistentes ${ }^{(16)}$. Outros estudos relatam o uso de diferentes técnicas de cultura no diagnóstico de ceratites fúngicas como o uso de hidróxido de potássio e calcofluor ${ }^{(17-19)}$. A sensibilidade das diferentes técnicas de cultura nestes estudos variou de 71 a $93 \%$, nos casos de culturas positivas ${ }^{(17-19)}$.

Neste estudo, como em outros semelhantes ${ }^{(1-6)}$, a MC mostrou-se uma importante ferramenta no diagnóstico, seguimento e acompanhamento do tratamento da ceratite fúngica. Esta investigação sugere que esta técnica rápida, segura e não invasiva, poderá diminuir a morbidade associada a esta doença agressiva e seu tratamento potencialmente tóxico.

\section{ABSTRACT}

The authors describe a case of fungal keratitis that the in vivo confocal microscopy helped in the diagnosis and follow-up. Confocal microscopy was done in a patient's ulcer that did not improve with several topical medicines. Corneal scrapings were obtained and culture results were without conclusion. We observed hyphae and infectious collections on confocal microscopy. New corneal culture showed Fusarium sp ten days after confocal diagnosis.

Keywords: Microscopy, confocal/methods; Córnea; Keratitis/ diagnosis; Eye infections, fungal; Fusarium; Case reports [publication type]

\section{REFERÊNCIAS}

1. Florakis GJ, Moazami G, Schubert H, Koester CJ, Auran JD. Scanning slit confocal microscopy of fungal keratitis. Arch Ophthalmol. 1997;115(11):1461-3.

2. Kaufman SC, Musch DC, Belin MW, Cohen EJ, Meisler DM, Reinhart WJ, et al. Confocal microscopy: a report by the American Academy of Ophthalmology.
Ophthalmology. 2004;111(2):396-406. Erratum in: Ophthalmology. 2004;111 (7):1306. Erratum in: Ophthalmology. 20041;111(7):1306.

3. Avunduk AM, Beuerman RW, Varnell ED, Kaufman HE. Confocal microscopy of Aspergillus fumigatus keratitis. Br J Ophthalmol. 2003;87(4):409-10. Comment in: Br J Ophthalmol. 2004;88(6):849; author reply 849-50.

4. Xie L, Li S, Shi W, Han D. [Clinical diagnosis of fungal keratitis by confocal microscopy]. Zhonghua Yan Ke Za Zhi. 1999;35(1):7-9, 3. Chinese.

5. Winchester K, Mathers WD, Sutphin JE. Diagnosis of Aspergillus keratitis in vivo with confocal microscopy. Cornea. 1997;16(1):27-31.

6. Chew SJ, Beuerman RW, Assouline M, Kaufman HE, Barron BA, Hill JM. Early diagnosis of infectious keratitis with in vivo real time confocal microscopy. CLAO J. 1992;18(3):197-201.

7. Mrukwa-Kominek E, Gierek-Lapinska A, Gierek-Ciaciura S, Rokita-Wala I. [Corneal scars: confocal images as the basis of qualifying for PTK or PK] Klin Oczna. 2001;103(1):29-34. Polish.

8. Xie L, Shi W, Liu Z, Li S. Lamellar keratoplasty for the treatment of fungal keratitis. Cornea. 2002;21(1):33-7. Comment in: Cornea. 2002;21(7):734-5; author reply 735 .

9. Victor G, Nosé W. Microscopia confocal in vivo em ceratocone: relato de caso. Rev Bras Oftalmol. 2001;60(12):853-8.

10. Victor G. Microscopia confocal. In: Alves MR, Chamon W, Nosé W. editores Cirurgia refrativa. Rio de Janeiro. Cultura Médica; 2003. p.44-6.

11. Liesegang TJ, Forster RK. Spectrum of microbial keratitis in South Florida Am J Ophthalmol. 1980;90(1):38-47.

12. McDonnell PJ, Nobe J, Gauderman WJ, Lee P, Aiello A, Trousdale M Community care of corneal ulcers. Am J Ophthalmol. 1992;114(5):531-8 Comment in: Am J Ophthalmol. 1992;114(5):630-2. Am J Ophthalmol. 1993; $115(3): 402-3$

13. O’Day DM, Akrabawi PL, Head WS, Ratner HB. Laboratory isolation techniques in human and experimental fungal infections. Am J Ophthalmol. 1979;87 (5):688-93.

14. Polack FM, Kaufman HE, Newmark E. Keratomycosis. Medical and surgical treatment. Arch Ophthalmol. 1971;85(4):410-6.

15. Jones DB, Wilson L, Sexton R, Rebell G. Early diagnosis of mycotic keratitis. Trans Ophthalmol Soc U K. 1970;89:805-13

16. Alexandrakis G, Jalali S, Gloor P. Diagnosis of Fusarium keratitis in an animal model using the polymerase chain reaction. Br J Ophthalmol. 1998;82(3):306-11

17. Vajpayee RB, Angra SK, Sandramouli S, Honavar SG, Chhabra VK. Laboratory diagnosis of keratomycosis: comparative evaluation of direct microscopy and culture results. Ann Ophthalmol. 1993;25(2):68-71.

18. Sharma S, Silverberg M, Mehta P, Gopinathan U, Agrawal V, Naduvilath TJ. Early diagnosis of mycotic keratitis: predictive value of potassium hydroxide preparation. Indian J Ophthalmol. 1998;46(1):31-5.

19. Chander J, Chakrabarti A, Sharma A, Saini JS, Panigarhi D. Evaluation of Calcofluor staining in the diagnosis of fungal corneal ulcer. Mycoses. 1993;36 (7-8):243-5.

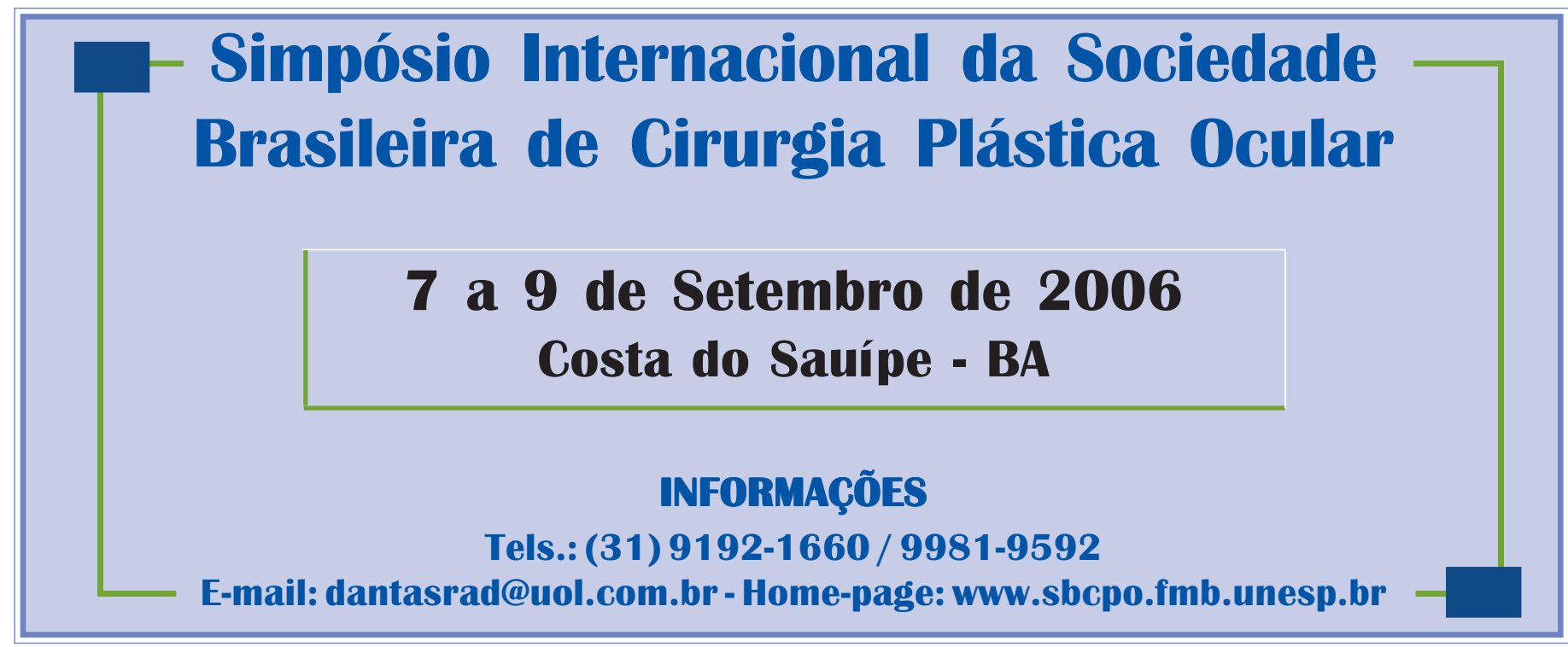

